\title{
Editorial: Measuring the Impact of the Child and Adolescent Social Work Journal
}

\author{
Jeffrey R. Lacasse ${ }^{1} \cdot$ Lisa Schelbe $^{1} \cdot$ Bruce A. Thyer ${ }^{1}$
}

Published online: 14 August 2015

(C) Springer Science+Business Media New York 2015

How do we know if our efforts are having an impact? How can we measure this, and how do we know if things are improving or getting worse? Many social workers in direct practice naturally ask themselves these questions. As academics, authors, and yes, journal editors, we often ask ourselves similar questions. Do the articles we publish have impact? Is Child and Adolescent Social Work Journal $(C A S W J)$ a "good" journal? These questions are probably most frequently asked by tenure-earning junior professors-publishing in quality publication outlets is famously an important part of the tenure process (i.e., Seipel, 2003). However, beyond tenure concerns, the assessment of scientific publications in social work is an important topic that social work academics have put substantial energy into over the years (e.g., Holden, Rosenberg, \& Barker, 2005). In this way, social work probably differs little from other fields in the academy, where bibliometric research is increasingly common.

The Impact Factor (IF) is the classic indicator of journal impact. Impact factor is the "average number of citations to published papers in the 2 years post-publication, by other subsequent papers in indexed journals" (Blyth et al., 2010, p. 122). In social science, the Thomson Reuters (previously ISI) database is standard. Articles that are cited in non-indexed journals do not count towards the impact factor of a journal. Due to the fact that many social work journals are not indexed in this database (including $C A S W J$ ), relying solely on IF as a measure of journal impact is problematic, as it can lead to an underestimation

Lisa Schelbe

1schelbe@fsu.edu

1 College of Social Work Florida State University, Tallahassee, FL, USA of journal impact. There are other problems with IF (well described in Blyth et al., 2010; see also PLoS Medicine Editors, 2006). So while IF is a well-established and useful metric, alternative measurement methods are clearly called for.

The $h$-index (Hirsch, 2005), developed by physicist Jorge Hirsch to measure research impact, is a desirable alternative. $H$-index represents the number of citations and quantity of publications in one number; a researcher or journal with an $h$-index of 15 has 15 publications that have been cited at least 15 times apiece (see Lacasse, Hodge, \& Bean, 2011). The use of the Google Scholar database to calculate journal $h$-index leads to a more inclusive method of measurement, as it captures journal citations in peerreviewed journals not indexed by Thomson Reuters. Through data analysis, Hodge and Lacasse (2011a) argue that the $h$-index may be a more empirically valid and appropriate manner of measuring journal impact in the field of social work than IFs. In a separate publication (Hodge \& Lacasse, 2011b), they ranked the top-80 disciplinary social work journals by 10-year $h$-index value. In 2011, $C A S W J$, although unranked by IF, was the 11th most highly ranked journal out of 80 by $h$-index score.

Since then, Google Scholar has integrated a journal metrics function which offers 5 -year $h$-index values for scientific journals. Unfortunately, the Google Scholar "Social Work" category includes a familiar problem (Thyer, 2012), as many of the listed journals are (at least arguably) not actually disciplinary social work journals. However, by simply entering "social work" into Scholar Metrics, the impact of $C A S W J$ relative to other journals can be assessed. On this list, CASWJ currently ranks \#18 out of the Top-20 journals displayed (http://tinyurl.com/CASWJh-index). The five-year h-index of $C A S W J$ is 14 , while Social Work Research is just ahead at 15 and Social Service 
Review and Journal of Social Work Education are at 16. We are in good company-and have been for some time. The goal of the editors and editorial board is now to push forward, and to further increase the impact and rigor of CASWJ.

In our minds, impact and rigor are highly connected. We believe the best way to increase our impact is to publish high-quality, topical articles (see Lee, Schotland, Bachetti, \& Bero, 2002). We seek submissions that address current issues relating to children and adolescents drawn from theory, direct practice, research, and social policy. CASWJ continues to invite a range of scholarly articles both empirical (e.g., single-system research designs, quasi-experimental and experimental evaluations) and non-empirical (e.g., theoretical papers, literature reviews). We value well-conceived, well-executed, rigorous research, and appreciate creativity and innovation.

An additional important element of a rigorous (and hopefully impactful) scientific journal is that it allows opportunities for critical discourse. In our opinion, the best journals take an open and non-defensive stance to criticism of work published in their pages, realizing science is a fallible human endeavor and that encouraging self-correction over time is the best remedy. For instance, Rubin and Parrish (2007) published a paper in Research on Social Work Practice (RSWP) pointing out that many authors publishing in RSWP were drawing conclusions unsupported by the data they presented (see also White, 1979).

In this issue, Dr. Jean Mercer, one of CASWJ's Editorial Board members, critiques an article previously published in this journal by Dr. Arthur Becker-Weidman (2006) on Dyadic Development Psychotherapy. Mercer (2015) argues that contra Becker-Weidman (2006), the current evidence is insufficient to consider Dyadic Development Psychotherapy as empirically supported. Mercer (2015) writes that editors and reviewers of academic journals play a central role in improving the rigor of academic literature and presents recommendations for the peer review process. This is an important issue that is increasingly recognized in the broader scientific community (Smith, 2006; Lacasse, 2011), and we are pleased to publish this article.

$C A S W J$ is committed to a rigorous peer review process which results in the publication of high-quality articles, thus enhancing the impact of our journal. Ultimately, though, we strive to publish quality work that has the potential to help social workers better serve children and adolescents. To accomplish this, we welcome suggestions, criticism, and submissions of high-quality scholarly work.

\section{References}

Becker-Weidman, A. (2006). Treatment for children with traumaattachment disorders: Dyadic developmental psychotherapy. Child and Adolescent Social Work Journal, 23(2), 147-171.

Blyth, E., Shardlow, S. M., Masson, H., Lyons, K., Shaw, I., \& White, S. (2010). Measuring the quality of peer-reviewed publications in social work: Impact factors-liberation or liability? Social Work Education, 29(2), 120-136.

Hirsch, J. E. (2005). An index to quantify an individual's scientific research output. Proceedings of the National Academy of Sciences of the United States of America, 102(46), 16569-16572.

Hodge, D. R., \& Lacasse, J. R. (2011a). Evaluating journal quality: Is the h-index a better measure than impact factors? Research on Social Work Practice, 21(2), 222-230. doi:10.1177/1049731510369141.

Hodge, D. R., \& Lacasse, J. R. (2011b). Ranking disciplinary journals with the Google scholar h-index: A new tool for constructing cases for tenure, promotion, and other professional decisions. Journal of Social Work Education, 47(3), 579-596. doi:10.5175/ JSWE2011.201000024.

Holden, G., Rosenberg, G., \& Barker, K. (2005). Bibliometrics in social work. New York: Routledge.

Lacasse, J. R. (2011). Reanalyzing a randomized controlled trial of combination antidepressant treatment with mirtazapine: Confidence intervals suggest substantial uncertainty. Ethical Human Psychology and Psychiatry, 13(2), 149-154. doi:10.1891/15594343.13.2.149.

Lacasse, J. R., Hodge, D. R., \& Bean, K. F. (2011). Evaluating the productivity of social work scholars using the h-index. Research on Social Work Practice, 21(5), 599-607. doi:10.1177/ 1049731511405069.

Lee, K. P., Schotland, M., Bachetti, P., \& Bero, L. A. (2002). Association of journal quality indicators with methodological quality of clinical research articles. JAMA, 287, 2805-2808.

Mercer, J. (2015). Revisiting an article about dyadic developmental psychotherapy: The life cycle of a Woozle. Child and Adolescent Social Work Journal, 32(5). doi:10.1007/s10560-015-0399-z.

PLoS Medicine Editors. (2006). The impact factor game. PLoS Medicine doi:10.1371/journal.pmed.0030291.

Rubin, A., \& Parrish, D. (2007). Problematic phrases in the conclusions of published outcome studies: Implications for evidence-based practice. Research on Social Work Practice, 17(3), 334-347.

Seipel, M. M. (2003). Assessing publication for tenure. Journal of Social Work Education, 39(1), 79-88.

Smith, R. (2006). The trouble with medical journals. London: Royal Society of Medicine.

Thyer, B. A. (2012). Some good news about Research on Social Work Practice. Research on Social Work Practice, 22(1), 5-9.

White, S. J. (1979). Statistical errors in papers in the British Journal of Psychiatry. British Journal of Psychiatry, 135, 336-342. 